Portland State University

PDXScholar

\title{
Students designing sustainability literacy and systemic change agent leadership curricula: an interconnected web approach at Portland State University
}

Angela L. Hamilton

Portland State University

Heather E. Spalding

Portland State University

Follow this and additional works at: https://pdxscholar.library.pdx.edu/iss_pub

Part of the Sustainability Commons

Let us know how access to this document benefits you.

\section{Citation Details}

Hamilton A. and Spalding, H. Students Designing Sustainability Literacy and Systemic Change Agent Leadership Curricula: An Interconnected Web Approach at Portland State University. The Journal of Record. February 2012, 5(1): 23-29.

This Article is brought to you for free and open access. It has been accepted for inclusion in Institute for Sustainable Solutions Publications and Presentations by an authorized administrator of PDXScholar. Please contact us if we can make this document more accessible: pdxscholar@pdx.edu. 


\title{
Students Designing Sustainability Literacy and Systemic Change Agent Leadership Curricula: An Interconnected Web Approach at Portland State University
}

\author{
By Angela L. Hamilton' and Heather E. Spalding²
}

Institutions of Higher Education (IHEs) recognize that there are many challenges to integrating sustainability into curriculum, including the large scale of the challenge itself, the existence of multiple curricula, creating connections between traditionally siloed disciplines, and the diverse types of postsecondary education institutions, but the deeper challenge "is that the existing curriculum in higher education has not been developed to examine how we shape a sustainable world" (p. 2). ${ }^{1}$ Examining and transforming the processes through which a sustainable world is envisioned and adapted is critical for sustainability literacy. According to The Handbook of Sustainability Literacy: Skills for a Changing World, edited by Arran Stibbe, "as people gain sustainability literacy skills, they become empowered to read self and society critically, to discover insights into the trajectory of society and to envisage where it is heading. They gain skills in re-writing self and society both in an effort to meet needs under increasingly difficult conditions and also to work towards new paths that lead to a more sustainable world" (p. 3). ${ }^{2}$ Sustainability literacy, therefore, is inherently acquired through the practice of change agent leadership. Reviewing several models of sustainability education learning outcomes, ${ }^{3-7}$ the following have been distilled to reflect the broad perspective of competencies of a sustainability change agent leader.

- Understanding ecological and whole systems $s^{3-5}$

- Understanding interconnectedness and relationship patterns ${ }^{3-6}$

- Forming perspectives of scale and local-global dialectics $^{3-6}$

- Modeling sustainable behavior and practices ${ }^{3-6}$

- Acquiring and practicing disciplinary or domain-specific sustainability skills ${ }^{3,5}$

- Demonstrating openness to new ideas and diverse perspectives and peoples ${ }^{3,5,7}$

No single discipline or other type of postsecondary curriculum can address the entirety of these systemic change agent leadership and sustainability

'Leadership for Sustainability Education, ${ }^{2}$ Sustainability Leadership Center, Institute for Sustainable Solutions, Portland State University, Portland, Oregon. literacy learning outcomes; therefore what is needed is an interconnected web approach across formal curricula, cocurricular programs, and extracurricular activities. Students are key stakeholders in the reorientation of curricula ${ }^{1}$ and by creating a collaborative network of faculty, staff, and community allies who move toward this common purpose, universities can ensure multiple pathways for experimenting, practicing, and advancing student sustainability literacy and leadership from entrylevel engagement to mastery. In fact, cocurricular education is such an integral part of student leadership development in higher education ${ }^{8}$ that sustainability educators, student affairs and sustainability administrators, and institutions should take advantage of the rich opportunity that cocurricular student sustainability leadership programs offer. Portland State University (PSU) programs provide students with an interconnected web of opportunities-in formal curricular, cocurricular, and extracurricular programs - for taking on leadership roles as designers of sustainability curricula across campus. This article profiles unique programs in which students play direct roles in curriculum design, highlights factors that have contributed to programmatic successes, and provides some recommendations for other postsecondary institutions based on lessons learned.

\section{Web of Opportunities}

Three primary avenues through which Portland State students have had the opportunity to design sustainability curriculum are formal curricular, cocurricular, and extracurricular programs. The formal curriculum programs profiled here are the Leadership for Sustainability Education (LSE) specialization within the Masters in Educational Leadership and Policy program and the Chiron Studies program. A cocurricular program through which students design curriculum is the Sustainability Leadership Center (SLC). Finally, the Sustainability Leaders Network (SLN) is an extracurricular student organization that has designed curriculum to engage students in sustainability learning opportunities.

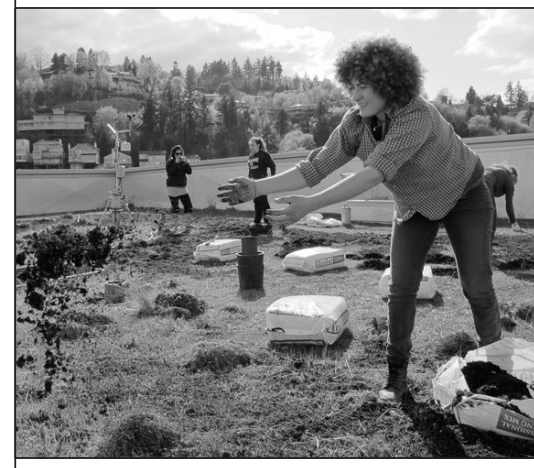

Residents of Broadway, a mixed use building on campus, replant the building's ecoroof with members of the Sustainability Volunteer Program and PSU staff.

Cocurricular education is such an integral part of student leadership development in higher education. 


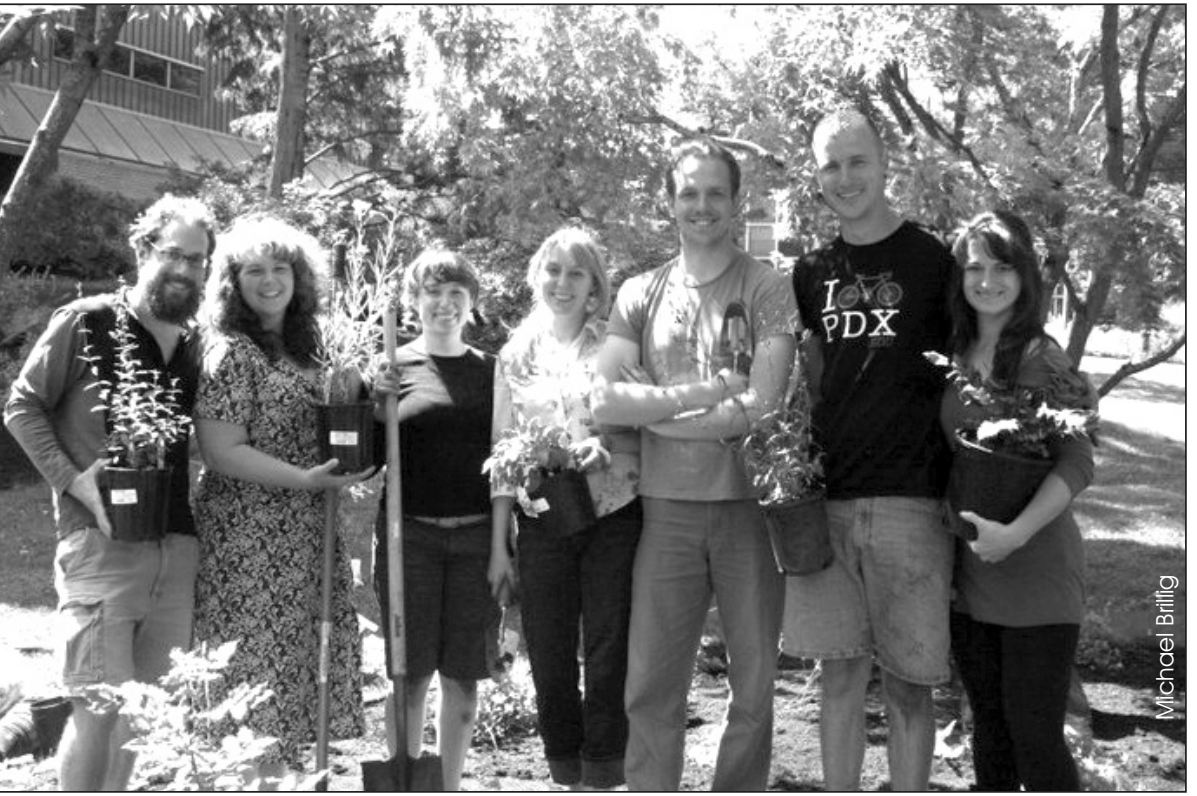

Sustainability Leadership Center staff members add new native plants to the Montgomery Street Permaculture Garden in the heart of campus.

At its core, the LSE program demonstrates the essence of interdisciplinary sustainability education, pedagogies, and curricula that model living systems principles.

\section{Leadership for Sustainability Education Specialization}

The LSE specialization within the Educational Leadership and Policy master's program is unique. Of the 26 master's programs listed on the Association for the Advancement of Sustainability in Higher Education (AASHE) website as academic programs in education, only three are titled as sustainability education; one is critical environmental education, and the other 22 are environmental education, ecological education, or outdoor education. It is also the only program listed that specifically incorporates leadership. The mission of the LSE is to prepare "graduates for professional careers in sustainability education through rigorous study of educational leadership and application of sustainability education pedagogical principles that address the importance of ecological systems, bio-cultural diversity, social and economic justice, and multicultural perspectives." ${ }^{\prime \prime}$ At its core, the LSE program demonstrates the essence of interdisciplinary sustainability education, pedagogies, and curricula that model living systems principles. The courses prepare students as sustainability literate change agents who "take leadership roles in envisioning and designing change and educating for sustainable solutions in our communities."

LSE students are often hired as graduate assistants in the Campus Sustainability Office, Learning Gardens Laboratory--a garden-based education programand PSURecycles! because of their capacity for contributing to research, assessment, program development, curriculum, and leadership. The LSE students become change agent leaders across campus as they design educational programs for the university that include responsible university purchasing practices, engaging peer mentors in institutional transformation, diverse perspectives of sustainability, garden-based education, and cocurricular education for sustainability leadership.

One recent LSE graduate complemented her classroom studies with a graduate assistant position in the Center for Academic Excellence. She convened focus groups to gather information about students' experience with and perceived needs regarding PSU's sustainability curriculum. She also collected and analyzed syllabi from self-identified sustainability-related courses, developed a coding system to analyze syllabi using grounded theory method, and synthesized the data into a report that was used to articulate a baseline for sustainability curriculum at PSU. This LSE student's research has been essential for the progress of campus sustainability curriculum and its contribution to the university's reporting to the Sustainability Tracking Assessment and Rating System (STARS).

The curriculum-oriented research has often developed out of the work in which the LSE students were already engaged on campus, and it has even grown into larger-scale curriculum change efforts by other students who chose to build upon their legacy under the guidance of supportive administration and faculty. In some cases, LSE graduates have transitioned into faculty positions teaching sustainability courses such as Introduction to Leadership for Sustainability; Gandhi, Zapata, and Topics in New Agrarianism; Permaculture and Whole Systems Design; and Environmental Education through a Native American Lens. A review of the course descriptions in the LSE master's program shows why graduates have a unique understanding of sustainability as a holistic concept, multicultural educational perspectives and practices, and clear ideas of how to apply living systems principles as sustainability education theory. They leave the program as change agent leaders for K-12 school systems, IHEs, organizations, and communities.

\section{Chiron Studies}

PSU's Chiron Studies program is another avenue through which students are actually being paid to design and teach four-credit undergraduate interdisciplinary studies courses not already offered in the university's curriculum. Like the LSE master's program, Chiron Studies is also "one of the only programs of its kind at a major university."10 Although it was not founded with an explicit sustainability focus, the instructors are currently encouraged to incorporate community engagement and sustainability components into their course design, which are the two areas of PSU's eight campus-wide learning outcomes that are the least developed. ${ }^{11}$ The emphasis on sustainability and community engagement provides a platform for students to design courses through which they become peer mentors, guiding others as agents of change for 
community sustainability. The program committee, which is comprised of students, faculty, and community members, is also led by student coordinators who each year work to improve the program's procedures, which include submitting an in-depth course proposal and syllabus. Fulfilling the submission requirements is a learning-by-doing activity in itself and requires the support of a faculty sponsor.

The Chiron Studies program and individual courses continue to build new institutional capacity beyond the end of the term. For example, students in the Food Affairs: Systems, Society \& Sustainability class engaged with the Northwest Earth Institute (NWEI) as a community partner by incorporating an NWEI food systems discussion course. As a result, participants in the class are forming a Food Action Collective student organization, seeking a food intern through the SLC, and requesting funding for the facilitation of design charettes that will result in a FoodWiki online hub.

\section{Sustainability Leadership Center}

The SLC currently employs one full-time sustainability leadership and outreach coordinator (SLOC), one half-time student leadership programs graduate assistant, six part-time student staff, and eight interns who design and implement leadership programs for the student community. Complemented by leadership workshops, events, and projects with shorter timelines, the core programs include the Sustainability Volunteer Program, Multicultural Task Force, EcoReps residence life program, and Student Sustainability Leadership Council (SSLC). As a cocurricular program that reports jointly to Student Affairs and the Institute for Sustainable Solutions, the SLC's mission includes facilitating sustainability literacy and systemic change leadership learning while engaging students in campus as a living laboratory and integrating sustainability into university leadership programs. This occurs through multilayered, peer-to-peer mentoring and collaboration across interconnected programs and projects.

The core mentoring circle consists of the SLOC and graduate assistant working closely to co-facilitate organizational, team, and individual student staff learning. From its launch in 2009, the SLC has been guided by philosophies of organizational learning and facilitative leadership. As a collaborative leadership practice, organizational learning and facilitative leadership are translated into emergent agenda design, potlucks and food sharing at meetings, check-ins, dialogue about leadership growth and challenges, consensus and participatory decision making, critical reflection through staff journals, stretch breaks, rotating facilitation, and team visioning. A web grows from authentic work relationships, which additionally extend beyond the inter-connected SLC staff and programs to crosspollinate ideas and resources across campus through collaborative partnerships with other cocurricular programs, departments, and student organizations.

The middle mentoring circle of the SLC emerges as the graduate assistant and student staff members develop their own program-specific learning outcomes and assessment plans. While still in the process of completion, in the summer of 2011 the SLC identified its overarching learning outcomes. Consultation was provided by the student affairs coordinator for assessment and research to ensure that SLC outcomes would be nested within campus-wide learning outcomes. The SLC employees are officially contributing to cocurricular learning and leadership outcomes for other students and are aware of how those learning outcomes relate to campus-wide learning outcomes. PSU is still making efforts toward integrating sustainability across the formal curriculum, but the SLC is on the leading edge because it involves students while they are in the process of identifying and assessing their own programmatic learning outcomes for sustainability. The SLC is also a model for change agent leadership because students are in positions of designing outcomes that may challenge traditional leadership styles, greenwashed sustainability, and linear assessment methods in order to reflect collaborative leadership, robust sustainability realms, and holistic assessment models.

The SLC's sustainability literacy and change agent leadership pathways have many entry points, but one model is to begin with the Sustainability Volunteer Program (SVP) and advance toward the SSLC or beyond into student staff and graduate assistant roles. It would be a challenge for the SLC to offer students compelling leadership development opportunities if they did not have diverse avenues for advancement. Modeling the importance of creating pathways through the web, the SLC itself is connected to other cocurricular leadership programs around campus and can advise students according to their interests and talents.

As an entry point, the SVP allows students to commit from two to four hours of engagement each week in order to connect with campus initiatives and be trained in sustainability skills as members of specific task forces such as Earth Week, Social Sustainability, ReUse Room, and Economic Sustainability. After one term in their positions, the SLC student staff may choose to create position descriptions and hire interns. The intern program reflects the outer circle of peer-to-peer mentoring that occurs through the SLC. Hiring is limited to students who have participated in an SLC program for at least one term. Internship roles include identifying new partnership opportunities, providing feedback and new perspectives, planning events, mentoring newer program

\section{Student-Taught Sustainability Courses in Chiron Studies}

- Documentary, Storytelling, and the Folk Tradition

- Natural Capitalism, Greenwashing, and Sustainability

- Alternative Energy Design and Build

- Food Affairs: Systems, Society \& Sustainability

\section{The Chiron}

Studies program and individual courses continue to build new institutional capacity beyond the end of the term. 
While the focus is on students having a collaborative team with whom to discuss and actively experiment in the application of their classroom learning, whenever such a group convenes, they typically incorporate aspects of sustainability literacy and change agent leadership learning. members, and managing specific projects. Interns are required to create personal leadership development plans and learning goals for the term, which allow the SLOC and the student staff with whom they work to track progress and guide critical reflection at the end of the term.

At a more advanced level of leadership engagement, the SSLC connects students who are already actively leading student initiatives. The student leadership programs graduate assistant convenes the SSLC and facilitates networking, leadership development, and designing student recommendations for university policy. The SSLC is convened using a collaborative systems design process that applies living systems principles, organizational learning, art of hosting, communities of practice, and action learning laboratory models as pedagogies for cocurricular sustainability leadership.

\section{Sustainability Leaders Network}

As an extracurricular student organization, the SLN serves as another avenue for students to design curriculum. Although the members are mostly students from the Leadership for Sustainability master's program, it is open to anyone on campus who is interested in the mission of "educating, networking, and nurturing leaders as change agents now for a sustainable future." 12 As a student-driven community of practice, members propose, design, and organize educational events such as movie nights, PSU's participation in National Sustainability Education Week, a week of sustainability-in-action events culminating in an Earth Day Festival, and a Sustainability Leadership Workshop designed as a multilevel action learning laboratory. While the focus is on students having a collaborative team with whom to discuss and actively experiment in the application of their classroom learning, whenever such a group convenes, they typically incorporate aspects of sustainability literacy and change agent leadership learning. The emphasis is on creating collaborative, engaged, just learning environments that model living systems principles as a means of activating leadership capacity within social, environmental, and economic sustainability domains.

The SLN established an official mentor relationship with Douglas Cohen, the co-chair of youth initiatives for U.S. Partnership for Education for Sustainable Development. As the mentor, Cohen's expertise and coaching have guided the student organization to build campus, community, and national partnerships; incorporate intergenerational learning opportunities; and practice sustainability education as change agent leaders. Through Cohen's coaching and the U.S. Partnership's campaign, each event has transformed into an opportunity to design educational experiences that engage students in an ongoing leadership learning journey.
An example of a multi-tiered action learning laboratory was modeled for the 2009 Sustainability Leadership Workshop, which brought together students, staff, and community members. Beginning as an approach supported by MIT's Center for Organizational Learning, the action learning laboratory is, as organizational learning expert Mitch Saunders defines, "a new method of understanding and creating change for leaders, organizations, and individuals" (p. 2). ${ }^{13}$ In this instance, a workshop planning team convened as an action learning lab in order to practice some of the methodologies themselves with newly recruited students who were interested in organizing the workshop. With varying degrees of success, students had a safe environment in which to experiment with this pedagogy for change agent leadership and reflect upon their experiences together. Through Cohen's coaching and the applied experience of facilitating an action learning lab, the planning team's skills evolved. For the final workshop, Cohen led an emergent action learning lab for all the participants while the planning team provided support. The workshop became a culminating learning experience for a cohort of student leaders who had begun their leadership learning journeys together two years earlier.

\section{Factors Contributing to Success}

There are many factors that contribute to the success of sustainability curriculum initiatives on any campus, and at a public university as large as PSU, there are many perspectives for identifying those key factors. In the case of student involvement in sustainability curriculum design at PSU, the web that interconnects curricular, cocurricular, and extracurricular sustainability literacy and systemic change agent leadership opportunities has emerged as a pattern. A strength of PSU's sustainability initiatives is that they are not confined to a department or program of study of their own; rather, they are interwoven across the university, which aligns with the systemic, transdisciplinary nature of sustainability education and brings greater awareness and access across campus. Despite the need to continue integrating sustainability across the curriculum, according to the Institutional Assessment Council, students have access to "courses at each level of the University Studies program" (p. 19) ${ }^{5}$ that address sustainability. They also report the need to determine cocurricular contributions to sustainability learning outcomes for students. Additionally, efforts are being made to document the course offerings and paint a picture of the overall sustainability curriculum on campusboth as a means of contributing to the campus-wide learning outcomes, which were established in March of 2009, and in order to further enhance PSU's Gold rating through the AASHE STARS program. Participation in programs such as STARS, and curriculum integration, in turn, create opportunities to involve 
graduate assistants, interns, and student staff who are studying education.

In the case of PSU's formal curriculum, there have been decades of foundational work that have contributed to the success of sustainability on campus. Parallel to and often integrated with the sustainability initiatives has been a strong sense of the need for engaging students in their community and campus through collaborative partnerships, service learning, internship programs, and more. The LSE master's program has community-based learning built into the curriculum, which allows students the flexibility of course hours to be actively applying their learning and getting credit for their activities. For every four-credit class, one credit hour is designated as a form of service-learning opportunity. This credit hour has been one of the ways that students can get credit for their cocurricular and extracurricular activities in a more holistic way than as a disconnected add-on.

A factor contributing to the success of initiatives all over campus, such as the Chiron Studies program, is that there are faculty and administrators who are willing to create opportunities for students to fill leadership roles and take on peer education. At PSU, common questions are, How do we get students more involved? and, What avenues can we create to incorporate more student voices? Intergenerational learning is also a key factor to sustainability education, and this requires finding ways to get more students in direct contact with people who are making decisions, designing programs, and implementing projects on campus.

For cocurricular and extracurricular student involvement in sustainability curriculum design, there are additional factors contributing to success. In the case of the SLC, the generous challenge grant to PSU from the James F. and Marion L. Miller Foundation cannot be overlooked because it has been the funding source for the SLOC's position as well as the entire SLC budget. From a more organizational development perspective, a contributing factor has been that when the SLC was launched and Heather Spalding was hired as the SLOC, she had a clear vision of what the students needed at that time. Spalding spent a lot of time establishing relationships with other cocurricular programs, various sustainability offices, and faculty who are teaching sustainability courses in order to promote the SLC as a resource for students and strategically build the interconnected web within which Spalding now operates. Spalding has also been transparent in her own learning processes as a sustainability educator and involves students to collaboratively learn as an organization. An attitude of transparency is essential for the sustainability journey as universities create new ways of learning and leading together.
One of the essential factors contributing to the success of the SLN is the availability of resources to students, made accessible through student fees. Fortunately, student activities programs are not unique to PSU. When students are new and still learning how to maneuver the bureaucracy of IHEs, having central access to student union venues for meeting and event spaces, funding for hosting workshops and educational programs, and having advisors to guide their organizational development and support their learning goals go a long way for students who may not otherwise know about the resources available to them. In the case of SLN, it has also been the avenue through which an external sustainability education advisor and other speakers can be contracted to provide some of the learning not available through formal curriculum or the cocurricular programs.

\section{Lessons Learned: Recommendations for Involving Students in Curriculum Design}

Overall, the above merely touches on a few of the factors that have contributed to the success of PSU students' involvement in curriculum design for sustainability literacy and change agent leadership. Most important is to share some of the lessons learned in the past few years that can potentially be helpful for other universities.

\section{General Initiatives and Formal Curriculum}

- Ensure that degree programs focus on sustainability as a holistic concept, not only environmental sustainability. Opportunities for vision alignment with other departments in the school of education might focus around the environmental justice aspects of social sustainability that connect to common emphases in schools of education through critical pedagogy and social equity. Philosophy of education courses are a good place to begin exposing students to the evolution of sustainability education.

- Let programs like Chiron Studies serve as a gauge for how well the university is doing in providing course offerings that meet student interests and needs. The pedagogy that students utilize-such as a rotating-facilitation discussion course-add other factors to consider beyond course content. In part, the success of a course should be measured by the passion and action leadership that it inspires in its students after their final grade.

- Demonstrate to administrators how sustainability education aligns with broader educational learning outcomes and pedagogies. Stay in the loop regarding local, state, national, and international educational policy and initiatives that set the big picture context of your institution's sustainability curriculum reorientation.
A factor contributing to the success of initiatives all over campus, such as the Chiron Studies program, is that there are faculty and administrators who are willing to create opportunities for students to fill leadership roles and take on peer education. 
Students who participate in programs that focus on and support the whole person as a unique leader will have greater capacity to transform organizations and be effective change agents in their future leadership roles.
- Keep alumni involved with the university as much as possible. Track and invest in graduate career paths to support the marketability of sustainability degrees. The institutions, businesses, and organizations where alumni work become natural community partners for your college or university. They can also provide opportunities for intergenerational learning, internships, and student mentoring.

- Create multiple access points and pathways through which students can get involved and advance along their leadership learning journeys. Provide incentives whenever possible. Incentives do not always have to be monetary, but sometimes financial incentives are needed to increase access for more diverse student involvement.

- Guide students who do not come from education-based disciplines to incorporate learning goals, critical reflection, service-learning, leadership, living laboratory immersion, and program assessment into their curriculum efforts in addition to what might be the focus of their discipline.

- Let the STARS criteria guide institutional priorities for student participation in designing, influencing, and engaging in sustainability curricula. STARS also serves as benchmark data that can justify future funding toward specific areas where more attention is needed.

- Recognize that sustainability as a concept and philosophy is not new, but rather a more holistic, systemic integration utilizing multiple perspectives and focusing on collaboration and common purpose to create a socially, environmentally, and economically stable society. Throughout IHEs, there are multiple pathways for how these realms are already being developed.

Involve students as much as possible! Hold forums to model inclusive engagement processes where students, faculty, and staff work together to design sustainability curriculum.

Become comfortable with knowing that systemic change cannot be fully tracked. Emergent transformation occurs in its own time and may not be easily recognizable until it has already occurred.

\section{Cocurricular Programs}

- Incorporate learning organization principles and leadership development strategies into student leadership programs in order to facilitate transformational learning, teamwork, and synergy for change. Students who participate in programs that focus on and support the whole person as a unique leader will have greater capacity to transform organizations and be effective change agents in their future leadership roles.
- Remember that human systems are living systems. Create a work environment where individuals can share their personal growth, challenges, and dreams in a supportive atmosphere. Share food and stories, take meetings outside on sunny days, and spend unstructured time outside the office to build authentic relationships. Support students' future success as change agents by prioritizing and modeling life balance and finding an appropriate work load.

- Capture student excitement and energy by creating a system that thrives on cross-pollination, collaboration, and generation of creative, new ideas. The organization should include enough structure to function effectively while also maximizing systems thinking and the capacity to constantly evolve as new information and feedback is synthesized.

- Find partners from across the university to cosponsor and cocreate the majority of programs the department focuses on. This becomes a way of working together to establish the interconnected web of relationships that integrates sustainability into existing programs.

- Engage student staff and program participants in creating the future of their organizations. This strategy creates self-identification with the program and increased personal, intrinsic responsibility for success of individual and group initiatives.

- Keep records of leadership growth, assessment toward learning outcomes, policies, procedures, and feedback. Make sure this documentation accurately describes the personalities and unique legacy of each member of the evolving living system.

- Plan for flexibility within student staff schedules and projects that allows students to explore their own interests and learning goals while still putting their curricular learning responsibilities first.

Remember that social sustainability initiatives

- take time to grow because they require relationship-building. Instead of continuing to ask how to get more people at the table, form strategic partnerships with key stakeholders. Do not give up if momentum is slow.

\section{Extracurricular Activities}

- Establish a means of documenting organizational memory to help acculturate new students into the student group and track achievements that need to be reported to the university to justify student group recognition.

- Consider how every event and meeting is an opportunity for learning. Plan in advance ways 
to intentionally design and facilitate the learning opportunities.

- Allow for emergence to occur and for the organization's mission and activities to adapt with the changing interests of the students involved.

- As soon as a positional leader within the organization takes office, begin to recruit for his or her replacement. Student turnover and the academic year cycle are particularly challenging aspects of ongoing student organization success; intentional recruitment and leadership transition is crucial. Continuity is even more difficult for student organizations made up of mostly graduate students.

- Create many opportunities for social activities that build relationships informally. Create a safe space for dialogue, experimentation, new ideas, diverse perspectives, and failure.

- Seek out mentors who as leadership and learning coaches can also connect the student organizations' activities to regional, national, and international sustainability initiatives. This brings visibility to the student group's success as a model for other universities and lets students see how their local activities relate to large-scale change movements.

- Be sure to celebrate successes and make it fun!

\section{Conclusion}

Providing students with opportunities to design curriculum and become actively involved in their own learning processes aligns with sustainability literacy and change agent leadership outcomes. Moving toward a socially, environmentally, and economically sustainable future calls for ongoing learning as we forge unforeseen paths. Formal curriculum, cocurricular programs, and extracurricular activities are only three avenues through which students can participate. Each institution should consider where they are best poised to let students take the lead in contributing to the web of sustainability curriculum initiatives.

\section{References}

1. Association for the Advancement of Sustainability in Higher Education (AASHE). Sustainability Curriculum in Higher Education: A Call to Action. Denver, 2010, p.2. http://www.aashe.org/files/A_ Call_to_Action_final\%282\%29.pdf (last accessed January 6, 2012)

2. Stibbe A, and Luna H. Introduction. In Stibbe A (ed.), The Handbook of Sustainability Literacy: Skills for a Changing World. Green Books, Totnes, England, 2009, p.11.
3. Washington Center for Improving the Quality of Undergraduate Education. Curriculum for the Bioregion Initiative: Building Concepts of Sustainability into Undergraduate Curriculum.Evergreen College Sustainability Learning Outcomes. Evergreen College, Olympia, WA. http://www.evergreen.edu/ washcenter/resources/upload/Integrating_Sustainability_Across_the_Curriculum.pdf (last accessed January 6, 2012).

4. Second Nature. Sustainability Curriculum Framework. Boston, MA. http://www.secondnature.org/ pdf/snwritings/factsheets/framework.pdf (last accessed January 6, 2012).

5. U.S. Partnership for Decade of Education for Sustainable Development. National Education for Sustainability K-12 Student Learning Standards, ver.3, Sept. 2009. http://s3.amazonaws.com/usp_ site_uploads/resources/152/USP_EFS_standards_ V3_11_10.pdf (last accessed January 6, 2012).

6. Portland State University, Institutional Assessment Council. Sustainability. Portland, OR. 2011. http://www.iac.pdx.edu/content/sustainability (last accessed January 6, 2012).

7. Yamasaki H. Personal communication with author Angela Hamilton, May 13, 2011.

8. Komives SR, Dugan JP, Owen JE, et al. The Handbook for Student Leadership Development, 2nd ed. Jossey-Bass, San Francisco, 2011.

9. Portland State University, Graduate School of Education: Educational Leadership \& Policy. LSE Program Overview. 2012. http://www.pdx.edu/elp/lseprogram-overview (last accessed January 6, 2012).

10. Portland State University, Chiron Studies. 2012. http://www.pdx.edu/chiron/ (last accessed January 6, 2012).

11. Institutional Assessment Council. Portland State University Campus-wide Undergraduate Learning Outcome 2010-2011, Assessment Report, 2011. http://iac.pdx.edu/sites/default/files/CWLO 20102011 Assessment Report.pdf (last accessed January 6, 2012).

12. Yamasaki H. Sustainability Leaders Network. Sustainability Leaders Network, Portland, Oregon, 2011.

13. Saunders M. Action Learning Labs: Turning Difficult Transitions into Breakthrough Opportunities. 2007.http://actionlearninglabs.com/wp-content/ pdf/action-learning-labs.pdf (last accessed January 6, 2012).
Providing students with opportunities to design curriculum and become actively involved in their own learning processes aligns with sustainability literacy and change agent leadership outcomes. 